\title{
Field Experiment on the Effects of a Nearby Asphalt Road on Temperature Measurement
}

\author{
Mariko Kumamoto ${ }^{1}$, Michiko Otsuka ${ }^{2}$, Takeshi Sakai ${ }^{1}$, Takashi Hamagami ${ }^{1}$, \\ Hiroshi Kawamura $^{1}$, Tadayoshi Aoshima ${ }^{1}$, and Fumiaki Fujibe ${ }^{2}$ \\ ${ }^{1}$ Meteorological Instruments Center, Japan Meteorological Agency, Tsukuba, Japan \\ ${ }^{2}$ Meteorological Research Institute, Tsukuba, Japan
}

\begin{abstract}
A field experiment to clarify the characteristics of temperature distribution near an asphalt car road was carried out at the Meteorological Instruments Center in Tsukuba, Japan. Fifteen thermometers equipped with artificially ventilated radiation shields were installed on a wide grass field within a distance of 10 $\mathrm{m}$ from edges of the road. At a height of $0.5 \mathrm{~m}$ above the ground, the temperature on the leeward side of the road was found to show substantial bias from that on the windward side of the road. The biases were positive values of $0.2-0.4^{\circ} \mathrm{C}$ on the average and larger when the thermometers was nearer to the road or in cases of lower wind speed. The temporal variation of the biases showed a diurnal change and had a maximum peak in the evening and negative values during some hours of the day. Smaller positive biases around $0.1^{\circ} \mathrm{C}$ were also found at a height of $1.5 \mathrm{~m}$ during some time of the day whereas small negative biases were seen at a height of $2.5 \mathrm{~m}$ in summer. These results indicate complicated distribution of roadside temperature, although they can partly be interpreted by advection of air heated over the road.
\end{abstract}

(Citation: Kumamoto, M., M. Otsuka, T. Sakai, T. Hamagami, H. Kawamura, T. Aoshima, and F. Fujibe, 2013: Field experiment on the effects of a nearby asphalt road on temperature measurement. SOLA, 9, 56-59, doi:10.2151/sola.2013-013.)

\section{Introduction}

Detection of climate changes based on observed temperature data can be affected by inhomogeneity arising from temporal variations in microscale environments around stations (Mahmood et al. 2006; Runnalls and Oke 2006; Pielke et al. 2007). As many observation stations in Japan are located in cities that have undergone rapid industrialization, more attention should be paid to evaluating the surroundings of such stations in terms of climate change monitoring. Fujibe $(2009,2011)$ described the possibility of microscale effects on observed temperature trends based on statistical analysis of wind speed and temperature for 29 years at around 300 stations in Japan. A field experiment at the KNMIterrain in De Bilt in the Netherlands showed that even minimal changes in site exposure could cause substantial differences in thermometer readings (Brandsma 2004).

Although temperatures are measured on the ground covered with short grass in operational stations of Japan Meteorological Agency (JMA), many of the sites are located within urbanized environment and surrounded by artificial surfaces such as buildings, car roads and car parks. According to the siting classification for surface observation stations on land in the CIMO Guide (WMO 2010), the main factors adversely affecting temperature measurements are regarded to be unnatural surfaces and shade. Thus, Class 1, 2, and 3 stations are required to be $100 \mathrm{~m}, 30 \mathrm{~m}$ and $10 \mathrm{~m}$ away from heat sources, respectively. Stations closer to heat sources (less than $10 \mathrm{~m}$ ) are classified into Classes 4 and 5 depending on the percentage of artificial surfaces within a circle

Corresponding author: Mariko Kumamoto, Meteorological Instruments Center, 1-2 Nagamine, Tsukuba 305-0052, Japan. E-mail: mkumamoto@ met.kishou.go.jp. (C2013, the Meteorological Society of Japan. of $10 \mathrm{~m}$ radius (less than $50 \%$ for Class 4 stations). However, there is little knowledge about how and to what extent nearby heat sources affect temperature observed in real settings of a site or its long-term data series, since several effects are so complicatedly mixed that it is difficult to separate and quantify the contribution from individual factors. A field experiment is a practical method for examining each factor under conditions where other factors can be neglected. Such experiments, however, require continuous observation using a set of thermometers that have a high reliability in order to detect microscale effects on long-term temperature data with an accuracy of climatological significance. The present study is focused on quantitative evaluation of effects of unnatural surfaces on temperature measurement on the basis of a field experiment, using fifteen thermometers installed around an asphalt road.

\section{Data and study method}

The experiment site was set up at the Meteorological Instruments Center of JMA in Tsukuba, Japan $\left(36^{\circ} 03.4^{\prime} \mathrm{N}, 140^{\circ} 07.5^{\prime} \mathrm{E}\right.$; Fig. 1). The site is surrounded by a flat open space covered with short grass, and is more than a few hundred meters away from buildings. There are no artificial heat sources or objects projecting shade within $100 \mathrm{~m}$ of the site, except for a $10 \mathrm{~m}$ wide asphalt car road crossing the site from east to west. The observations were conducted continuously in summer (30 June to 1 October 2010) and winter (29 November 2010 to 6 January 2011) to include various patterns of advection in the vicinity of the road. The grass was green in summer, with a height of 10 to $20 \mathrm{~cm}$, and was mowed four times from July to August, although there was no irrigation on the experiment field during the data acquisition period. In winter the grass was brown with a height of $10 \mathrm{~cm}$ or less.

The layout of the instrumentation used is shown in Fig. 1. Four sampling points were set on the northern side of the road for the summer period, and on the southern side for the winter period, so that they were on the leeward of the road with respect to prevailing winds, which are southerly in summer and northwesterly in winter. They were aligned with an angle of about 70 degrees from the road, with distances of $0.8 \mathrm{~m}, 3.2 \mathrm{~m}, 6.9 \mathrm{~m}$ and $10.0 \mathrm{~m}$ from the edge of the road. Thus the road occupied $45 \%, 30 \%$, $10 \%$ and $0 \%$ of the area within a $10 \mathrm{~m}$ circle of each sampling point, corresponding to Class 5, 4, 3, and 3 stations in the WMO siting classification, respectively. At each sampling point, three thermometers were installed at heights of $0.5 \mathrm{~m}, 1.5 \mathrm{~m}$ and $2.5 \mathrm{~m}$ from the ground. It should be noted that operational observation of surface air temperature is made at a height of $1.5 \mathrm{~m}$. In addition, three thermometers were placed on the opposite side of the road at a distance of $10.0 \mathrm{~m}$ from its edge, at the same three levels as those at other sampling points, in order to observe reference temperatures. All the thermometers were of the same model as those used in the Automated Meteorological Data Acquisition System (AMeDAS) of JMA, and were installed inside radiation shields with artificial ventilation. The sensors of the thermometers (Pt $100 \Omega, 6 \mathrm{~mm}$ in diameter) were calibrated in a liquid bath-type measurement chamber before and after the experiment installation to allow adjustment of the observed values.

In addition to temperature, several other parameters were measured in the experiment. Two ultra-sonic anemometers and 

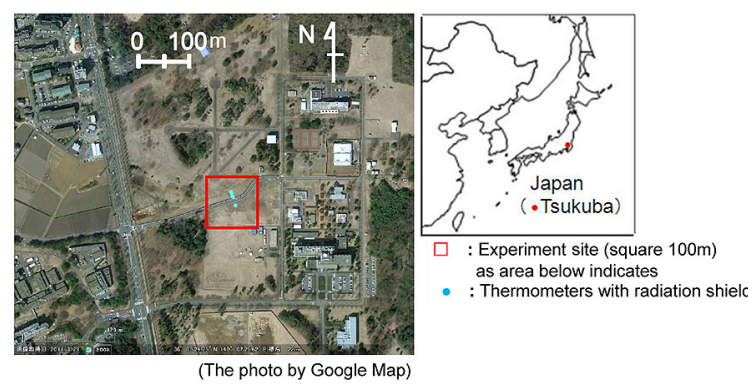

Location of the experiment site
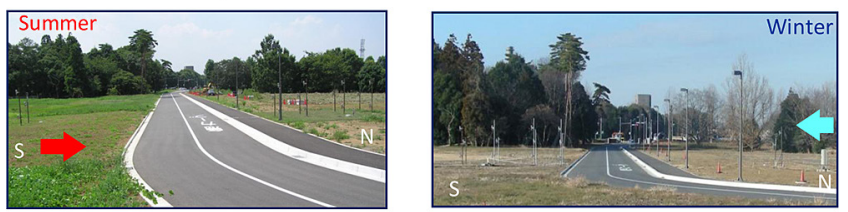

30 June -1 October 2010
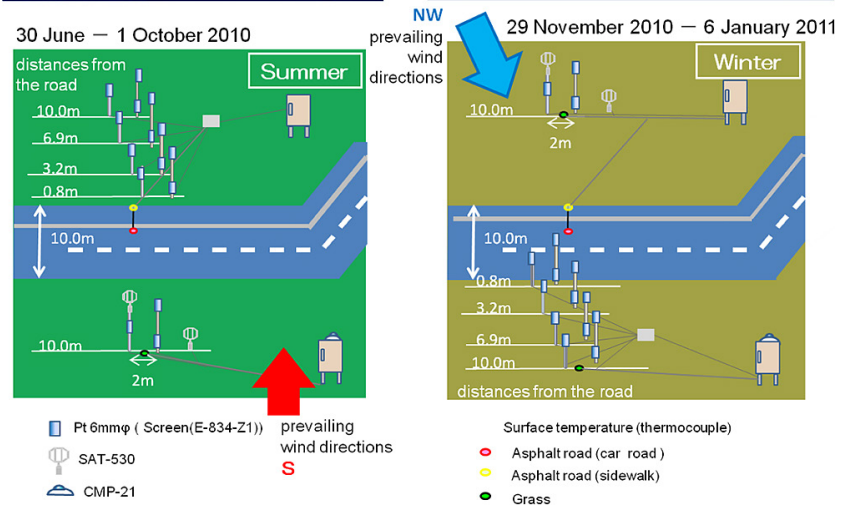

Fig. 1. Location of the experiment site (top), photograph of the site (middle) and layout of instrumentation (bottom). a pyranometer were installed to monitor the in-situ wind speeds and the weather conditions at the site. The anemometers were mounted at the heights of $0.5 \mathrm{~m}$ and $2.5 \mathrm{~m}$ near the reference point (Fig. 1). The road surface temperature was measured by using a thermocouple thermometer fixed directly on the asphalt surface. On the grass field, another thermocouple thermometer was installed to monitor the grass surface temperature, at about $3 \mathrm{~cm}$ above the ground because it was impossible to fix it directly on the grass or the ground. In addition, surface temperature distribution around the site was observed using a radiation thermometer (THERMO-TRACER TH7100) on 16 August, 3 September, and 5 January.

The data sampling frequency for the thermometers, the thermocouple thermometers and the pyranometer was 1.0 second, and that for the anemometers was 0.25 second. For the thermometers and the thermocouple thermometers, six ten-second values were averaged into a one-minute value, in the same way as in operational temperature data processing. This way of processing is also in accordance with the CIMO Guide (WMO 2010), which recommends six or more values to be averaged for processing a one-minute temperature value. For the anemometers, 3-second moving averages of the 0.25 -second sample data were used.

The temperature departure from the reference point, $\delta T$, is defined as

$$
\delta T=T-T_{0},
$$

where $T$ and $T_{0}$ are temperatures at a sampling point and the reference point of the same height, respectively.

\section{Results}

Figure 2 presents the frequency distributions of $\delta T$ values at each height of each sampling point in summer and winter. For summer, data for wind directions from ESE to SSW were grouped into southerly cases, because differences in frequency distribution
Summer: 30 Jun. - 1 Oct. 2010

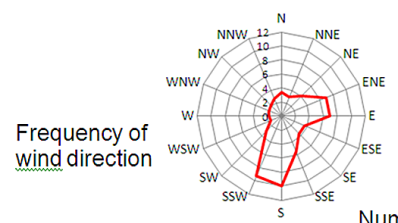

Winter: 29 Nov. 2010 - 6 Jan. 2011

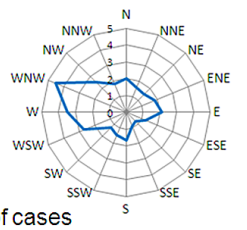

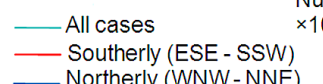

Southerly (ESE - SSW)

(a) $2.5 \mathrm{~m}$

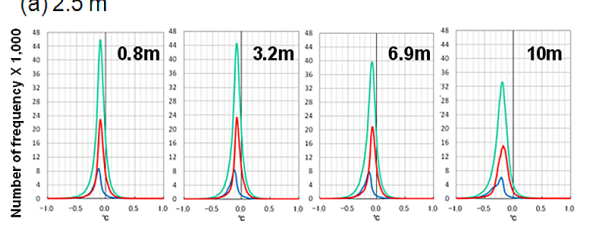

(b) $1.5 \mathrm{~m}$

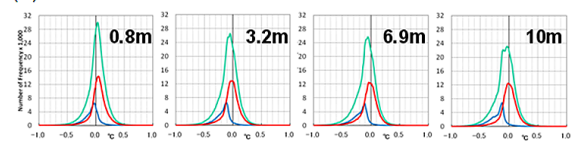

(c) $0.5 \mathrm{~m}$

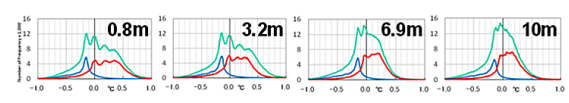

(d) $2.5 \mathrm{~m}$

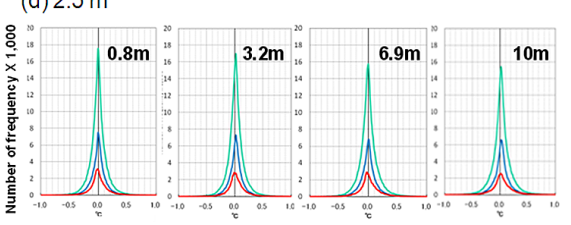

(e) $1.5 \mathrm{~m}$

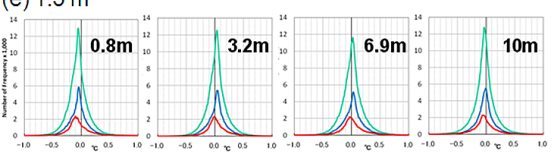

(f) $0.5 \mathrm{~m}$
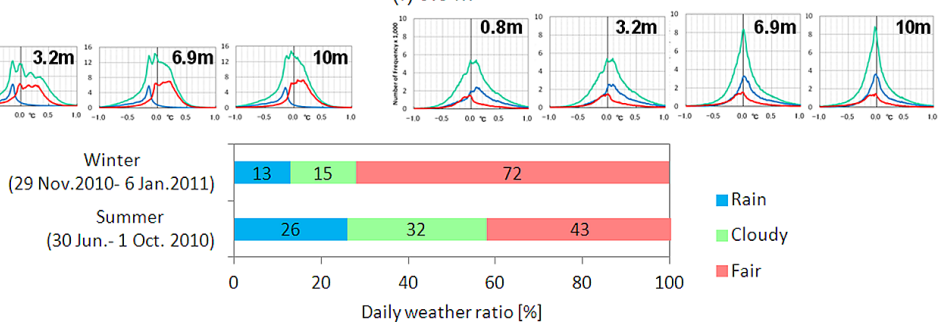

Fig. 2. Frequency distribution of wind direction (top, 16 points of compass) and $\delta T$ at each height and sampling point (middle, a-f) for each observation period. The frequency of $\delta T$ is shown in the total number of one-minute values that fall on each $0.01^{\circ} \mathrm{C}$ interval. Daily weather ratio diagram for each period is shown in the bottom, where "rain" is defined by daily rainfall amount of at least $1 \mathrm{~mm}$, "cloudy" is defined by no rain with cloud amount (averaged of 09 JST and 15 JST) of at least $8.5 / 10$, and "fair" is defined by other cases. 
among these wind directions were found to be small (see Fig. S1 for details). Likewise, data for winds from WNW to NNE were grouped into northerly cases. For southerly winds, the sampling points were located on the leeward side of the road, and for northerly winds they were located on the windward side. In the same manner, the winter cases were categorized into groups of southerly winds (ESE-SW) and northerly winds (WNW-NE) (see Fig. S2 for details).

For the summer period, the frequency distributions of $\delta T$ at a height of $0.5 \mathrm{~m}$ show positive biases for southerly winds (ESESSW) and negative biases for northerly winds (WNW-NNE). The bias for southerly winds is 0.2 to $0.4^{\circ} \mathrm{C}$, and tends to be larger at shorter distances from the road. Positive biases at a height of $0.5 \mathrm{~m}$ are also seen in winter under northerly winds, although they are smaller than those observed in summer. Thus, positive temperature biases at $0.5 \mathrm{~m}$ are seen in both summer and winter on the leeward side of the road.

At a height of $1.5 \mathrm{~m}$ above the ground, biases are much smaller than at the $0.5 \mathrm{~m}$ height. On the other hand, significant negative biases are seen regardless of wind direction at a height of $2.5 \mathrm{~m}$ for summer, especially at the farthest point $(10 \mathrm{~m}$ from the road). In order to check the reliability of this result, three among the five thermometers at the height of $2.5 \mathrm{~m}$ (at $6.9 \mathrm{~m}$ and $10.0 \mathrm{~m}$ northward from the road, and at $10.0 \mathrm{~m}$ southward from the road) were checked in a bath-type chamber on 26 August, but there was no indication of drift from the initial calibration made before the observation period (4 and 7 June 2010). For the sake of further confirmation, the thermometer at the $2.5 \mathrm{~m}$ height at 10.0 $\mathrm{m}$ northward from the road was changed to a new one on the next day, but there were negative biases invariably before and after the replacement (see Fig. S3 for details).

Figure 3 shows the frequency distributions of $\delta T$ in relation to wind speed in summer, for southerly wind cases in which the surface temperature difference between the road and the grass was greater than $10^{\circ} \mathrm{C}$. At a height of $0.5 \mathrm{~m}, \delta T$ is positively biased with both the average and the range of variation larger for cases of lower wind speed. At a height of $1.5 \mathrm{~m}, \delta T$ ranges from $0.0^{\circ} \mathrm{C}$ to $0.2^{\circ} \mathrm{C}$ regardless of the distance from the road, and $\delta T$ has negative biases at a height of $2.5 \mathrm{~m}$. More detailed results and discussions are described by Hamagami et al. (2012), including those of winter cases.
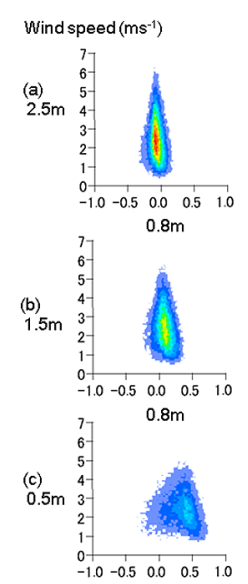

$0.8 \mathrm{~m}$
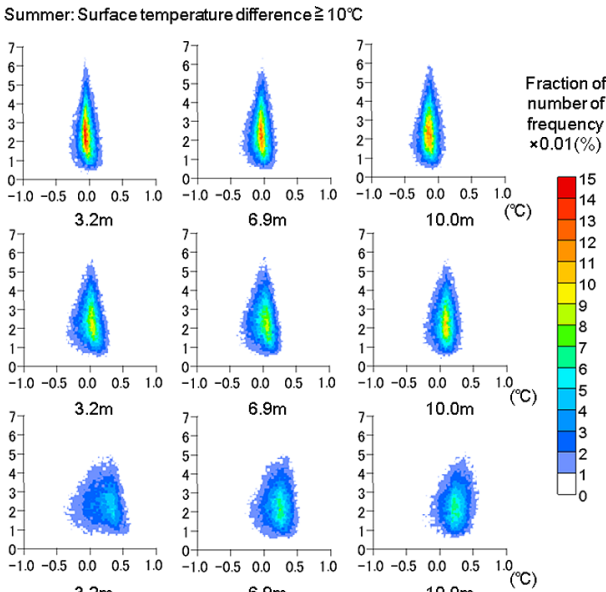

Fig. 3. Frequency distribution of $\delta T$ by wind speed at each height and each sampling point, for summer cases in which the surface temperature difference between asphalt and grass was $10^{\circ} \mathrm{C}$ or more. The frequency indicates the percentage of values that belong to each grid having a $0.01^{\circ} \mathrm{C}$ interval in $\delta T$ and $0.1 \mathrm{~m} \mathrm{~s}^{-1}$ interval in wind speed.

Figure 4 shows the averaged diurnal variations in $\delta T$, surface temperatures of the road and the grass field, and wind speeds for middle summer (MS: 17 July to 31 August 2010) and middle winter (MW: 6 December 2010 to 6 January 2011). All values shown in Fig. 4 are based on ten-minute moving averages of each parameter. During the two periods, there were not much differences in wind directions between day and night, although wind speed tends to be higher in the daytime than in the nighttime, in which wind direction sometimes had a large fluctuation (A typical example is shown in Fig. S4).

In MS, the surface temperature of the road rose to $55^{\circ} \mathrm{C}$ during the peak hours of 1200-1400 Japan Standard Time (JST) and remained above $30^{\circ} \mathrm{C}$ during the night, being $6-14^{\circ} \mathrm{C}$ higher than that of the grass field all through the day. The results of radiometrybased measurement confirmed that the surface temperature was

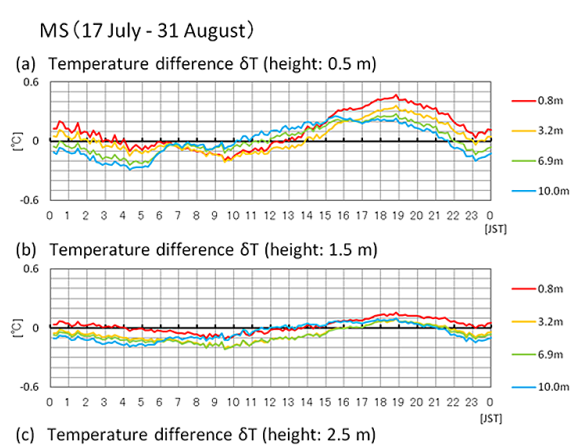

(c) Temperature difference $\delta \mathrm{T}$ (height: $2.5 \mathrm{~m}$ )
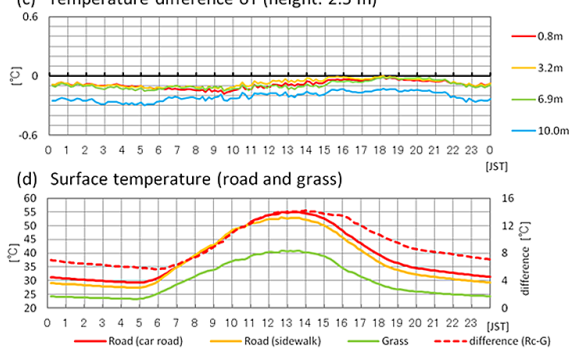

(e) Wind speed

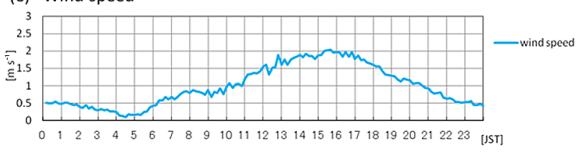

MW (6 December - 6 January)

(f) Temperature difference $\delta \mathrm{T}$ (height: $0.5 \mathrm{~m}$ )

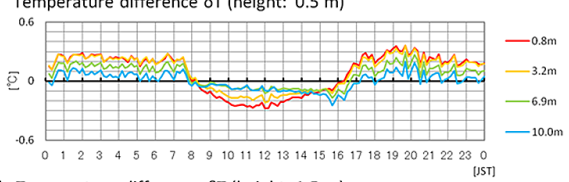

(g) Temperature difference $\delta \mathrm{T}$ (height: $1.5 \mathrm{~m}$ )

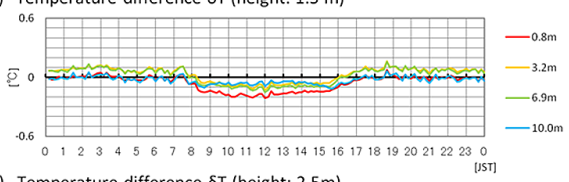

(h) Temperature difference $\delta \mathrm{T}$ (height: $2.5 \mathrm{~m}$ )

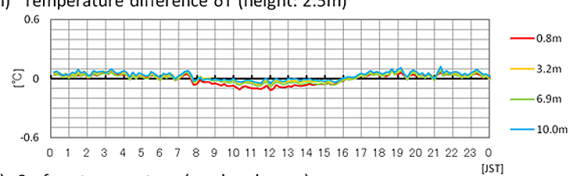

(i) Surface temperature (road and grass)

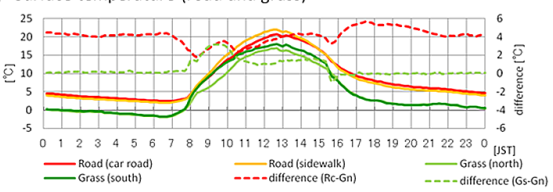

(j) Wind speed

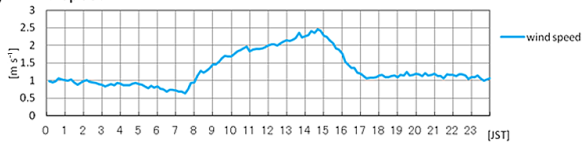

Fig. 4. Diurnal variations of $\delta T$, surface temperature and wind speed for MS (left panels) and MW (right panels). In the panel (d), "Rc$G$ " indicates the difference between the car road and grass. In (i), "Rc-Gn" indicates the difference between the car road and the grass of the northern side, and "Gs-Gn" indicates the difference between the grass of the southern and northern sides. 
almost uniformly distributed over each of the two surface types. The diurnal variation of $\delta T$ at a height of $0.5 \mathrm{~m}$ is characterized by a uni-modal pattern having a maximum in early evening, with a largest amplitude at the point nearest the road ( $0.8 \mathrm{~m}$ distance), where the maximum value of $\delta T$ is $0.47^{\circ} \mathrm{C}$ around 1900 JST. On the other hand, there are small negative biases during the hours of 0700-1200 JST, although the road surface temperature is higher than on the grass. Diurnal variations with a similar pattern are found also at the $1.5 \mathrm{~m}$ height, although the amplitudes are much smaller than at $0.5 \mathrm{~m}$. At the height of $2.5 \mathrm{~m}, \delta T$ remains slightly negative throughout a day at all the sampling points.

In MW, positive biases in $\delta T$ are conspicuous all throughout the night, with a peak at around 1900 JST at a height of $0.5 \mathrm{~m}$, under a lower wind speed of about $1.0 \mathrm{~m} \mathrm{~s}^{-1}$ and larger temperature differences between the road and grass surfaces than in the daytime. The peak magnitude of $\delta T$ is slightly lower than that in MS. In the daytime, negative biases in $\delta T$ are seen near the road with a peak at $1200 \mathrm{JST}$, although surface temperature is $2-4^{\circ} \mathrm{C}$ higher on the road than on the grass.

\section{Summary and remarks}

The experiment has revealed that the effects of a nearby asphalt road on temperature measurement vary depending on wind speeds, wind directions, distances from the road, and heights above the ground. In case that the thermometers were on the leeward side of the road, temperatures at a height of $0.5 \mathrm{~m}$ were found to show significant positive biases on the average. There was a diurnal variation in which a maximum bias was found at around 1900 JST both in summer and winter and negative biases tended to occur during some parts of the day, while surface temperature was higher over the road than over the grass throughout a day. At a height of $1.5 \mathrm{~m}$, which is the standard height for temperature observation, the temperature bias on the average was much smaller than that at a height of $0.5 \mathrm{~m}$, but still there were some biases of the order of $0.1^{\circ} \mathrm{C}$ during some hours of the day (Fig. 4). Though the bias on a short time scale of every ten seconds sometimes fluctuated within the scale of one to two degrees depending on wind conditions or other environmental causes during the day (as seen in Fig. S4 (a)-(e)), it was thus reduced in magnitude when averaged for some period of time. On the other hand, the bias at a height of $2.5 \mathrm{~m}$ was negative on the average over the summer period.

The positive bias of the average temperature at a height of $0.5 \mathrm{~m}$ implies the direct influence of the road, where air is expected to be heated and transported by the wind. However, the presence of negative biases in some period of the day, and at a height of 2.5 $\mathrm{m}$, indicates that the temperature distribution is not so simple as to be fully explained by advection from the heated road surface. In other words, the roadside temperature appears to have a complicated distribution in spite of the simplicity of the site environment, which is an unexpected result of this study. At present it is difficult to give satisfactory explanation to the complication, although a possible interpretation to the negative biases may be the effect of vegetation that were located $100-200 \mathrm{~m}$ of the site (Fig. 1).

The target of the present study is the effect of a $10 \mathrm{~m}$-wide road, but the effect of larger artificial surfaces, which are commonly found around stations in urban areas, should yet to be investigated. It is also necessary to examine other factors such as the presence of buildings and trees, terrain roughness, heat balance, and soil moisture, in order to further understand the mechanism by which temperature measurement is affected by the surrounding environment. Such types of field experimentation, as well as computer simulation, are expected to enhance expertise on methods of evaluating the environmental conditions of observation stations.

\section{Acknowledgments}

The authors are deeply grateful to Dr. Watanabe and the reviewers for giving suggestions to improve the manuscript. We also would like to thank Mr. Kotaro Bessho for his helpful advice with the manuscript. This work was partly supported by Grant-inAid for Scientific Research (No.22340141) of Japan Society for the Promotion of Science.

\section{Supplement}

Figure S1: Frequency and distributions of $\delta T$ for each wind direction from 30 June to 1 October 2010.

Figure S2: Same as Fig. S1, but for 29 November 2010 to 6 January 2011.

Figure S3: Comparison of frequency distributions of $\delta T$ at a height of $2.5 \mathrm{~m}$ before and after 26 August, on which the thermometer at $10.0 \mathrm{~m}$ northward from the road was changed to a new one.

Figure S4: A typical example of diurnal variation in $\delta T$ and other variables (22 August 2010).

\section{References}

Aoshima, T., K. Nakashima, H. Kawamura, M. Kumamoto, T. Sakai, S. Kawano, and M. Joko, 2010: RIC-Tsukuba (Japan) intercomparison of thermometer screens/shields in 20092010. WMO Technical Conference on Meteorological and Environmental Instruments and Methods of Observation (TECO-2010), 31 August 2010, Helsinki, Finland. (http:// www.wmo.int/pages/prog/www/IMOP/publications/IOM104_TECO-2010/P3_1_Aoshima_Japan.pdf; http://www.jma. go.jp/jma/jma-eng/jma-center/ric/material/4_Reports/3-1_ TECO poster.pdf)

Brandsma, T., 2004: Parallel air temperature measurements at the KNMI-terrain in De Bilt (the Netherlands) May 2003-April 2005, Interim report. KNMI-publicatie 207 HISKLIM 7, 29 pp.

Fujibe, F., 2009: Relation between long-term temperature and wind speed trends at surface observation stations in Japan. SOLA, 5, 81-84.

Fujibe, F., 2011: Urban warming in Japanese cities and its relation to climate change monitoring. Int. J. Climatol., 31, 162-173.

Hamagami, T., M. Kumamoto, T. Sakai, H. Kawamura, S. Kawano, T. Aoyagi, M. Otsuka, and T. Aoshima, 2012: Field experiment on the effects of a nearby asphalt road on temperature measurement. 16th Symposium on Meteorological Observation and Instrumentation, 92nd American Meteorological Society Annual Meeting, January 22-26, 2012. (https://ams.confex.com/ams/92Annual/webprogram/ Paper200202.html)

Mahmood, R., S. A. Foster, and D. Logan, 2006: The GeoProfile metadata, exposure of instruments, and measurement bias in climatic record revisited. Int. J. Climatol., 26, 1091-1124.

Pielke, R. A., C. A. Davey, D. Niyogi, S. Fall, J. SteinwegWoods, K. Hubbard, X. Lin, M. Cai, Y.-K. Lim, H. Li, J. Nielsen-Gammon, K. Gallo, R. Hale, R. Mahmood, S. Foster, R. T. McNider, and P. Blanken, 2007: Unresolved issues with the assessment of multidecadal global land surface temperature trends. J. Geophys. Res., 112, D24S08, doi:10.1029/2006JD008229.

Runnalls, K. E., and T. R. Oke, 2006: A technique to detect microclimatic inhomogeneities in historical records of screen-level air temperature. J. Climate, 19, 959-978.

WMO, 2010: Guide to Meteorological Instruments and Methods of Observation. WMO-No. 8 (2008 edition, updated in 2010). (http://www.wmo.int/pages/prog/www/IMOP/CIMOGuide.html)

Manuscript received 18 February 2013, accepted 27 March 2013 SOLA: http://www.jstage.jst.go.jp/browse/sola 